12 years. There is clearly a need for a new and more emphatic approach to this health hazard.

In general, the picture portrayed by the 1970 British Births Survey is one of continuing, steady progress with lowering mortality rates, but there is no doubt that much can still and must be done to improve the care of pregnant women in Britain. We must strive to identify more precisely those pregnancies where there is an increased risk and ensure that special attention and skills are given to these mothers. Equally important is the need to explore every means of educating the mothers themselves so that every advantage is taken of facilities at present available.

${ }^{1}$ Reports on Confidential Enquiries into Maternal Deaths in England and Wales 1952-1972. London, HMSO, 1957-1975.

${ }^{2}$ Maternity in Great Britain: Report of the 1946 Survey. London, Oxford University Press, 1948.

${ }^{3}$ Butler, N R, and Bonham, D G, Perinatal Mortality. Edinburgh, E and S Livingstone, 1963.

${ }^{4}$ Butler, N R, and Alberman, E D, Perinatal Problems. Edinburgh, E and S Livingstone, 1969.

${ }^{5}$ British Births 1970, The First Week of Life. London, Heinemann, 1975.

${ }^{6}$ Illsley, R, British Medical fournal, 1955, 2, 1520.

\section{Whose responsibility?}

The important lesson of the inquiry into St Augustine's Hospital, Chartham, Canterbury, ${ }^{1}$ is that no one took overall responsibility for the care of the patients with chronic mental disorders. The rest of the staff saw the consultant psychiatrists as leaders; and, says the report, they were content to be so cast, but they did nothing to lead the long-stay wards away from custodial care. In consequence the nurses-struggling to cope in overcrowded, disturbed wards with less than adequate staff-set themselves the objective of keeping their patients quiet and out of trouble and nothing more. No one need be surprised that in such a depressing environment there were examples of ill treatment and neglect.

Unlike its predecessors, however, this inquiry has made positive suggestions for reform that could lead to a fundamental change in attitudes. It argues a convincing case for multidisciplinary teams at three levels-hospital, clinical area, and ward-which would agree on treatment policies and on the way they should be put into practice. These teams would include doctors, nurses, administrators, psychologists, social workers, occupational therapists, and representatives from the patients, and would be responsible for setting standards and ensuring that they were met.

Over-stretched as the psychiatric services are, at present the chronic patients in many long-stay wards get little attention from medical staff dealing most of the time with the overwhelming load of acute mental illness. The multidisciplinary approach would give the nurses and therapists who spend their working days with chronic patients a chance to initiate variations in treatment and help formulate policies on the management of violence and the handling of complaints and would encourage activities such as outings for patients. This team concept would introduce no conflict with clinical responsibility, for, while a diagnosis or the prescription of a drug by a doctor may be influenced by information provided by a psychologist or a nurse, the final responsibility is, and must remain, his.

The second initiative in the St Augustine's report is its emphasis on the need for effective surveillance of standards of care. "Far too much monitoring consists of waiting to be told and then taking no effective action when information does come," says the report, and it is only too clear that a monitoring system may degenerate into a complaints procedure. What is needed-not only in mental hospitals but elsewhere in the NHS -is a more positive approach to medical audit, for constructive criticism has an important role in improving clinical standards.

Too much optimism would, unfortunately, be unrealistic; for there is one major obstacle to these proposals. Almost any mental hospital could embark on a programme of revitalisation of therapeutic effort in its long-stay wards, carrying along medical and nursing staff in a wave of enthusiasm, and some have already done so. But, as we have emphasised so often before, ${ }^{2-4}$ such treatment programmes must have discharge from hospital as their long-term objective; and most of the communities into which the patients would be discharged have done little to provide accommodation or other facilities for them. There can be no coherent policy for the treatment of mental illness so long as the community services remain so grossly inadequate.

\footnotetext{
${ }^{1}$ Report of committee of inquiry at St Augustine's Hospital, Chartham. South-east Thames Regional Health Authority, 1976.

2 British Medical fournal, 1966, 2, 655

${ }^{3}$ British Medical fournal, 1973, 3, 1.

${ }^{4}$ British Medical fournal, 1976, 1, 111.
}

\section{Food choking and the "Heimlich maneuver"}

"Each year, 3900 healthy individuals in the United States
strangle because of food stuck in their throats. The actual
incidence is probably much higher, as indicated by a report of
unsuspected food choking found at postmortem examinations
of three patients thought to have died from myocardial
infarctions in one nursing home last year." So opened a
dramatic article in 7 A $A A^{1}$ by Dr Henry J Heimlich, who went
on to describe the "Heimlich maneuver," a procedure designed
to disimpact a food bolus lodged at the laryngeal orifice. This
depends on a quick upward thrust on the diaphragm by
pressure on the epigastrium in an inward and upward direction.
The idea is to produce a sudden sharp rise of intrathoracic
pressure which will eject the bolus like a cork out of a bottle.
The procedure can be performed with the casualty standing
or lying. The article also describes a standard signal for "I am
choking on food," in which the victim graspshis neck between
the index finger and thumb: the idea is that bystanders will
then be alerted to act swiftly and effectively.
The incidence of these so-called café coronaries appears to
be higher in the United States than in Britain. Category E911
in the International Classification of Diseases includes
"inhalation and ingestion of food causing obstruction or
suffocation." There were 176 deaths in Britain from this cause
in 1972 among men and women aged 3-59 years and a further
121 among those aged 60 or more.
deaths in babies, but some at least of these must have been
examples of the sudden infant death syndrome diagnosed in
old-fashioned terms. Further examination of these deaths show
that most occur in old people in institutions and a few in
young adults who vomit after drinking alcohol.

In Britain, then, the problem does not seem large-possibly because the potentially lethal practice of drinking whisky with 
steak is less usual here. Nevertheless, there does seem to be a case for bringing the "Heimlich maneuver" to the attention of all who could save life by employing it, and in practice that means the general adult population. First-aid teachers and health educators take note.

${ }^{1}$ Heimlich, H J, Fournal of the American Medical Association, 1975, 234, 398.

2 Adelstein, A M, unpublished data, 1976.

\section{Violence and television}

A recent article in the fournal of the American Medical Association lamented the standard of television for children there and called for an organised cry of protest from the medical profession about what, in political terms, was described as a "national scandal."

Calculations suggest that the average American child will have viewed some 15000 hours of television by the time he has graduated from high school, as compared with some 11000 hours of formal classroom instruction. He will, it seems, have witnessed some 18000 murders and countless highly detailed incidents of robbery, arson, bombing, forgery, smuggling, beating, and torture-averaging approximately one per minute in the standard television cartoon for children under 10. There is on average six times more violence during one hour of children's television than in an hour of adult television. Furthermore, by the time a child has reached 18 years he will have had some 35000 television commercials directed at him $-25 \%$ of the television industry's profit is said to come from the $7 \%$ of its children's programmes.

There has been a steady flow of research on the effects of television viewing, nearly all of it pointing in the same direction. Two early endeavours ${ }^{2} 3$ were still able to find control groups of children not yet exposed to television, and these firmly established that there is no single answer to the question of how television affects children, but that different children selectively use whatever is available according to their particular needs. While most take television in their stride some lonely and handicapped children become addicted. Subsequent research has been much concerned with the effects of viewing violence. One such study ${ }^{5}$ showed that children aged 5-6 consistently imitate aggressive filmed models. Another study 6 reviewed 146 published papers representing 50 studies and 10000 children and adolescents from every sort of background, all showing that the watching of violence produces increased aggressive behaviour in the young, and confirming the progression from an unsatisfied need, to selective watchfulness and observation, to imitation, and, through practice, to a lasting addition to the repertoire of behaviour.

Despite a very thorough American inquiry ${ }^{7}$ reported in no fewer than six volumes by the Surgeon General's Scientific Advisory Committee, and despite the publication of television codes and guidelines for children's television programmes, American practice is still a source of great concern.

In Britain this concern is not so much about the quality of children's programmes, which are generally considered to be excellent, as about the quality and quantity of the programmes for adults which many children watch. Most would agree that children's television such as Play School, Blue Peter, and Magpie are well adapted to the time of showing and therefore to the available age-sector of viewing children, and that the programmes are positively beneficial. The Walt Disney-type animal cartoons are certainly full of violence, but of such a stylised nature that few parents or pedagogues raise an eyebrow, and even experimental psychologists would probably find the happenings so far removed from reality as to be no stimulus to identification and imitation. Programmes such as the Lone Ranger, Robin Hood, and Dr Who have their quota (somewhat refined, if not respectable) of violence; it may be argued that anyway children need to recapitulate the stages of social evolution and in doing so they may as well have good models before them as bad.

It is certainly proper to be eternally vigilant about children's programmes and about the degree of commercial intrusion therein; if the facts are as stated, we should support the American call for reform. Yet the content of programmes is not our only responsibility. Some disturbed children (and adults) will search for deviant solutions and will sooner or later find them; their need is for recognition of their problem and help in finding an acceptable solution. Children will always (and perhaps even should) watch a proportion of adult programmes; what is important is the response those children see from their parents, and that the parents should be concerned to watch for any distress and to deal with it appropriately. In such ways stress may be advantageous. No degree of programme refinement will absolve, or substitute for, parental responsibility.

\footnotetext{
'Rothenberg, M B, fournal of the American Medical Association, 1975, 234, 1043.

${ }^{2}$ Himmelweit, H T, Oppenheim, H M, and Vince, P, Television and the Child. London, Nuffield Foundation and Oxford University Press, 1958.

${ }^{3}$ Schramm, W, Lyle, J, and Parker, E B, Television in the Lives of our Children. London, Oxford University Press, 1941.

4 Kniveton, B H, and Stephenson, J M, British fournal of Psychiatry, 1973, $122,53$.

5 British Medical fournal, 1973, 2, 565.

${ }^{6}$ Libert, R M, Neale, J M, and Davidson, E S, The Early Window: Effects of Television on Children and Youth. Oxford, Pergamon Press, 1973.

7 Technical Report to the Surgeon General's Scientific Advisory Committee. Washington, United States Government Printing Office, 1972.
}

\section{Immunosuppressive therapy in SLE-a reappraisal}

For over a decade now cyclophosphamide and azathioprine (and to a lesser extent chlorambucil) have been widely used in the management of systemic lupus erythematosus, particularly in those patients with severe renal lesions. Use of these drugs seemed logical in a disease characterised by such widespread immunological overactivity, and the dramatic improvement in prognosis achieved by similar therapy in another vasculitic disease, Wegener's granulomatosis, ${ }^{1}$ suggested even to the most sceptical that it might have potential benefits in lupus. Unfortunately the widespread clinical experience now accumulated with these drugs in SLE has not been matched by a parallel number of controlled trials.

The major studies to date have been largely confined to patients with renal SLE and in general have suggested that either cyclophosphamide or azathioprine given in combination with prednisone will produce more benefit (in terms of creatinine clearance, urea, and serum complement) than either drug given alone. ${ }^{2-5}$ Azathioprine reduced proteinuria and improved creatinine clearance, cut the number of hospital admissions, and resulted in a steroid-sparing effect averaging $10 \mathrm{mg} /$ day. ${ }^{5}{ }^{6}$ The second of these studies did not, however, show any additive effect with high dose prednisone in treating 